\title{
Open-Angle Glaucoma: Drug Development Pipeline during the Last 20 Years (1995-2015)
}

\author{
André Vicente $^{a, b}$ Sylvie Prud'homme ${ }^{d}$ Joana Ferreira ${ }^{b, c}$ Luís Abegão Pinto ${ }^{b}$ \\ Ingeborg Stalmans ${ }^{d}$

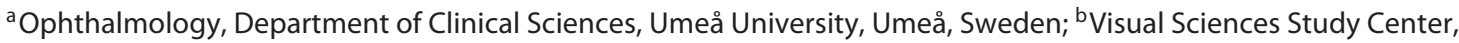 \\ Faculty of Medicine, Lisbon University, and 'Department of Ophthalmology, Centro Hospitalar Lisboa Central, \\ Lisbon, Portugal; ${ }^{d}$ Department of Ophthalmology, University Hospitals Leuven, Leuven, Belgium
}

\section{Key Words}

Open-angle glaucoma . Drug development . International Clinical Trials Registry Platform

\begin{abstract}
Objectives: To analyse drug development for open-angle glaucoma during the last 20 years. Methods: Research was performed by referring to clinical trials registered at the International Clinical Trials Registry Platform (ICTRP). A search for the condition "open-angle glaucoma" with the intervention "drug" was performed. We included trials registered from $01 / 01 / 1995$ to $01 / 01 / 2015$, only involving studies in phases 1,2 , and 3 . Only studies resorting to novel treatment strategies (either novel drugs or yet-untested fixed associations of approved medication) were considered. Results: We recorded 158 studies for the condition of open-angle glaucoma with a drug-based intervention; 65 of the studies reported phase 2 trials and 74 reported phase 3 trials. Pharmaceutical companies were the primary sponsors of $95.3 \%$ of the trials. Most of the studies $(66.5 \%, n=105)$ involved a new drug, and the remainder $(33.5 \%, n=53)$ tested fixed
\end{abstract}

\section{KARGER}

(C) 2017 S. Karger AG, Basel

E-Mail karger@karger.com

www.karger.com/ore drug associations. The bulk of the trials ( $n=99,62.7 \%$ ) involved the use of prostaglandin analogues, either as a comparator or a study drug. In descending order of frequency, the studies conducted involved Rho-kinase inhibitors ( $n=$ 15), carbonic anhydrase inhibitors $(n=14), \beta$-blockers $(n=$ 7), angiostatic steroids $(n=6), a_{2}$-adrenergic agonists ( $n=$ 4), $5-\mathrm{HT}_{2 \mathrm{~A}}$ receptor agonists $(n=4)$, and NMDA receptor antagonists $(n=2)$. A cyclin-dependent kinase inhibitor, an LIM-domain kinase 2 inhibitor, an A1 adenosine receptor agonist, catechin, macrolide, saffron, and seawater were each tested in 1 clinical trial. Conclusion: Research into the medical treatment of glaucoma indicates the use of prostaglandin analogues. However, there are a significant number of trials testing other drug classes, particularly Rho-kinase inhibitors. This new focus could lead to a potential increase in the number of therapeutical options for the management of glaucoma in the future.

(c) 2017 S. Karger AG, Basel

A.V. and S.P. contributed equally to this paper and should be considered first co-authors. 


\section{Introduction}

Glaucoma is one of the most prominent causes of irreversible blindness in the world, with a global prevalence of $3.45 \%$ among people $40-80$ years of age. It is estimated that approximately 111.8 million people will have glaucoma by 2040 [1]. The modifiable risk factor for glaucoma is high intraocular pressure (IOP). The compression of this ocular parameter continues to be the mainstay of glaucoma treatment, either requiring medical treatment (usually topical instillation of IOP-lowering agents) or surgery [2].

Glaucoma medical treatment has evolved in the last few decades from IOP modulators (such as pilocarpine and timolol) to myriad new drugs that seek to exploit new treatment paradigms [3]. Some of the limitations related to the existing IOP-lowering therapies include harmful side effects, a significant proportion of non-responders, and the need for combination therapy to achieve target IOP [4].

Accordingly, there is an unmet need that has driven research into new combination therapies and novel treatment paradigms. Moreover, as IOP represents one risk factor but does not explain the entire pathophysiology of the disease [5], investment into research of glaucoma drugs that function through other mechanisms is now occurring. Some of the more recent approaches include molecules that influence ocular haemodynamics and neuroprotective agents [6].

The translation of novel therapies from bench to bedside is a protracted process, involving multiple phases before the promising drug candidates reach the clinic $[7,8]$. The purpose of this study is to provide an overview of the clinical trials registered for the treatment of primary open-angle glaucoma with novel drug candidates over the last 20 years as well as a view to identify emerging trends in the field.

\section{Methods}

A systematic search of the International Clinical Trials Registry Platform (ICTRP) was performed. This platform was established in 2006 by the World Health Organization, with the objective of disclosing information about all the clinical trials that involve human beings. Thus, the platform requires publication of an internationally agreed-upon set of information about the design, conduct, and administration of clinical trials [9]. The ICTRP database includes registrations from ClinicalTrials.gov and the European Union (EU) Clinical Trial Register, among others.

A query was performed according to the optimized search protocols in this database [10]. Accordingly, the search for the condition "open-angle glaucoma" with the intervention "drug" was performed. The interval for the registration of research was from $01 / 01 / 1995$ to $01 / 01 / 2015$. Only studies on phase 1,2 , and 3 trials were included. There were no restrictions on the recruitment status
Table 1. Overview of drug-related clinical trials in open-angle glaucoma in 1995-2015

\begin{tabular}{|c|c|c|c|c|c|c|}
\hline $\begin{array}{l}\text { Year } \\
\text { registered }\end{array}$ & $\begin{array}{l}\text { Phase } \\
1\end{array}$ & $\begin{array}{l}\text { Phase } \\
2\end{array}$ & $\begin{array}{l}\text { Phase } \\
3\end{array}$ & $\begin{array}{l}\text { Phases } \\
1+2\end{array}$ & $\begin{array}{l}\text { Phases } \\
2+3\end{array}$ & Total \\
\hline 1995 & 0 & 0 & 3 & 0 & 0 & 3 \\
\hline 1996 & 0 & 0 & 2 & 0 & 0 & 2 \\
\hline 1997 & 0 & 0 & 1 & 0 & 0 & 1 \\
\hline 1998 & 0 & 1 & 0 & 0 & 0 & 1 \\
\hline 1999 & 0 & 1 & 1 & 0 & 1 & 3 \\
\hline 2000 & 0 & 0 & 2 & 0 & 0 & 2 \\
\hline 2001 & 0 & 0 & 5 & 0 & 0 & 5 \\
\hline 2002 & 0 & 1 & 1 & 0 & 0 & 2 \\
\hline 2003 & 0 & 2 & 2 & 0 & 0 & 4 \\
\hline 2004 & 0 & 1 & 3 & 0 & 0 & 4 \\
\hline 2005 & 0 & 2 & 7 & 0 & 0 & 9 \\
\hline 2006 & 0 & 4 & 3 & 1 & 0 & 8 \\
\hline 2007 & 1 & 9 & 2 & 0 & 0 & 12 \\
\hline 2008 & 0 & 8 & 5 & 1 & 2 & 16 \\
\hline 2009 & 0 & 7 & 6 & 1 & 0 & 14 \\
\hline 2010 & 1 & 4 & 9 & 1 & 0 & 15 \\
\hline 2011 & 1 & 7 & 12 & 2 & 0 & 22 \\
\hline 2012 & 1 & 7 & 1 & 2 & 0 & 11 \\
\hline 2013 & 1 & 7 & 3 & 0 & 0 & 11 \\
\hline 2014 & 0 & 4 & 6 & 3 & 0 & 13 \\
\hline Total & $\begin{array}{l}5 \\
(3.2 \%)\end{array}$ & $\begin{array}{l}65 \\
(41.1 \%)\end{array}$ & $\begin{array}{l}74 \\
(46.8 \%)\end{array}$ & $\begin{array}{l}11 \\
(7.0 \%)\end{array}$ & $\begin{array}{l}3 \\
(1.9 \%)\end{array}$ & 158 \\
\hline
\end{tabular}

or the countries involved. All trials regarding already-approved medication were excluded. An exception was made when a trial compared an approved medication with a new agent, or when a new agent was being used in combination with an approved medication.

The following parameters were recorded from each of the trials: trial ID, date of last update on trial status, public title, scientific title, acronym, primary and secondary sponsor, date of registration, source register, recruitment status, minimum and maximum age for inclusion, gender inclusion, exclusion and inclusion criteria, date of enrolment, target size, study type, phase, study design, countries involved, conditions, interventions, and primary and secondary outcomes. The mechanism of action for each compound was determined by evaluating the published literature. Only the main component was considered in the case of fixed associations. For drugs with $>1$ suggested mechanism, classification was performed by considering the primary mode of action.

All descriptive statistical analysis was performed using SPSS v18.0 (IBM Corp., Armonk, NY, USA).

\section{Results}

The query provided 158 entries registered between $01 / 01 / 1995$ and $01 / 01 / 2015$. Of these, only 4 had been directly registered in the ICTRP. One hundred and fiftythree were initially submitted to ClinicalTrials.gov $(n=$
202

Ophthalmic Res 2017;57:201-207

DOI: $10.1159 / 000453527$
Vicente/Prud'homme/Ferreira/

Abegão Pinto/Stalmans 
Fig. 1. Overview of the drug-related clinical trials in open-angle glaucoma during the 1995-2015 period.

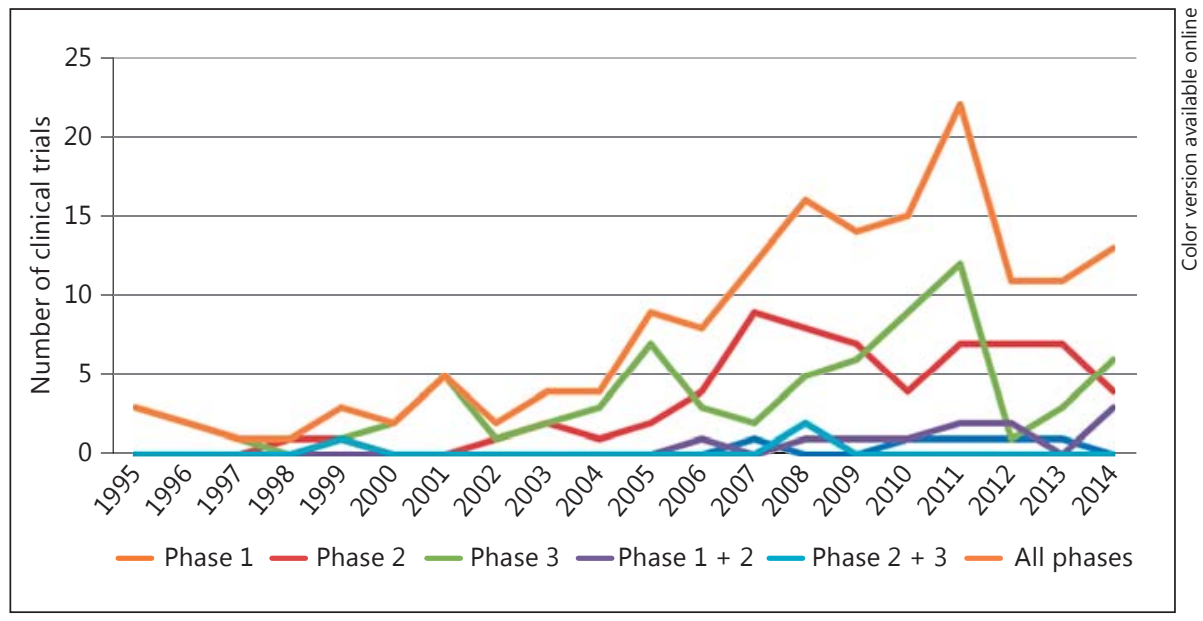

$149)$ and 5 to the EU-related database. Nearly the entire set of entries had been registered by the pharmaceutical industry $(n=150)$.

The vast majority of entries involved phase 2 and 3 trials (65 [41.1\%] and 74 [46.8\%], respectively), with only 5 studies in the earliest phase. A significant number of trials (14 [8.9\%]) covered more than a single phase (i.e., either phases $1+2$ or phases $2+3)$, and these were categorized separately (Fig. 1; Table 1). In $66.5 \%(n=105)$ of the trials, a single new drug was being tested. In $33.5 \%(n=53)$ of the identified trials, fixed associations of drugs were being tested, and only $24.5 \%(n=13)$ of these were associated with a new drug. Only $5.1 \%(n=8)$ of the selected clinical trials were still actively recruiting patients.

There was missing data in the ICTRP database for $22.2 \%(n=35)$ of the registered clinical trials. Phase 1 clinical trials lacked information in $20 \%(n=1)$, phase 2 in $16.9 \%(n=11)$, and phase 3 in $31.1 \%(n=23)$ of the registered trials.

Geographical analysis was possible in all but 12 studies. Out of these 146 studies, the majority (64.3\%) were performed in the USA. EU countries accounted for almost $15 \%$ of the total of study locations, and the remaining 20\% were conducted elsewhere (Fig. 2).

Information on the target size sample was available in $88.0 \%(n=139)$ of the trials, with a large heterogeneity between studies (mean \pm SD, $246.2 \pm 264.2$ ). The minimum recruitment age was available in $93.7 \%(n=148)$ of the studies, whereas the maximum age was registered in only 21 trials and was, on average, $76.6 \pm 11.1$ years. Only 1 trial included children $<18$ years $(0.6 \%, n=1)$. All the analysed clinical trials included both males and females.

Drug Development for Glaucoma in the Last 20 Years

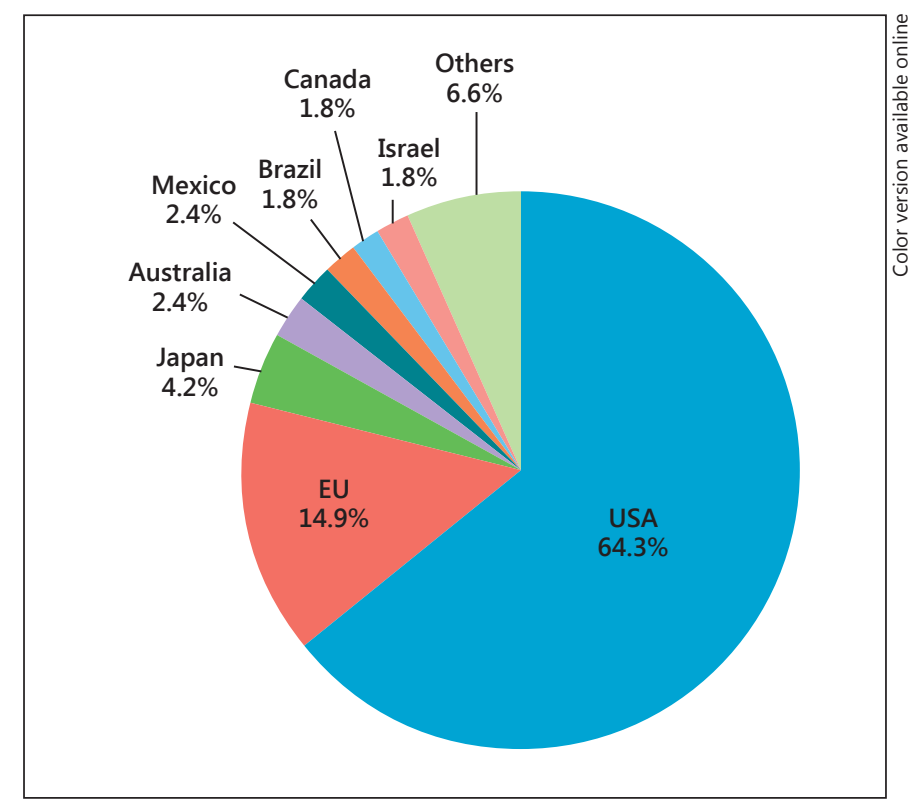

Fig. 2. Distribution of the clinical trials by region.

The descriptive analysis of the different mechanisms of action for the test drugs is detailed in Table 2. IOP modulation was the most common mechanism of action of the drugs in the clinical trials $(87.2 \%, n=138)$. Drugs that combine IOP modulation and neuroprotection were tested in $10.1 \%$ of the trials $(n=16)$; drugs that function by enhancing neuroprotection were tested in $1.9 \%(n=$ $3)$. Prostaglandin analogues were the drugs tested in the majority of the trials $(62.7 \%, n=99)$, most of which were phase 3 trials $(n=57)$. The Rho-kinase inhibitors ranked second $(9.5 \%, n=15)$, with carbonic-anhydrase inhibi-

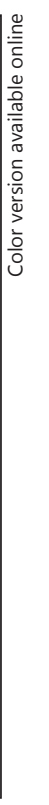

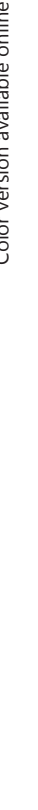


Table 2. Mechanisms of action and different classes of drugs in the clinical trials researched

\begin{tabular}{|c|c|c|c|c|c|c|}
\hline & Phase 1 & Phase 2 & Phase 3 & Phases $1+2$ & Phases $2+3$ & Total \\
\hline \multicolumn{7}{|l|}{ IOP modulation } \\
\hline Prostaglandin analogues & 4 & 34 & 57 & 4 & 0 & $99(62.7 \%)$ \\
\hline Carbonic anhydrase inhibitors & 0 & 3 & 10 & 0 & 1 & $14(8.9 \%)$ \\
\hline$\beta$-Blockers & 0 & 4 & 2 & 1 & 0 & $7(4.4 \%)$ \\
\hline Angiostatic steroids & 0 & 4 & 0 & 0 & 2 & $6(3.8 \%)$ \\
\hline$\alpha_{2}$-Adrenergic agonist & 0 & 2 & 1 & 1 & 0 & $4(2.5 \%)$ \\
\hline $5-\mathrm{HT}_{2 \mathrm{~A}}$ receptor agonists & 0 & 4 & 0 & 0 & 0 & $4(2.5 \%)$ \\
\hline Cyclin-dependent kinase inhibitors & 0 & 1 & 0 & 0 & 0 & $1(0.6 \%)$ \\
\hline LIM-domain kinase 2 inhibitor & 0 & 0 & 0 & 1 & 0 & $1(0.6 \%)$ \\
\hline A1 adenosine receptor agonists & 0 & 1 & 0 & 0 & 0 & $1(0.6 \%)$ \\
\hline Macrolide & 1 & 0 & 0 & 0 & 0 & $1(0.6 \%)$ \\
\hline Subtotal & 5 & 53 & 70 & 7 & 3 & $138(87.2 \%)$ \\
\hline \multicolumn{7}{|l|}{ Neuroprotection } \\
\hline NMDA receptor antagonists & 0 & 0 & 2 & 0 & 0 & $2(1.3 \%)$ \\
\hline Catechin & 0 & 0 & 0 & 1 & 0 & $1(0.6 \%)$ \\
\hline Subtotal & 0 & 0 & 2 & 1 & 0 & $3(1.9)$ \\
\hline \multicolumn{7}{|l|}{ IOP modulation + neuroprotection } \\
\hline Rho-kinase inhibitors & 0 & 11 & 2 & 2 & 0 & $15(9.5 \%)$ \\
\hline Saffron & 0 & 1 & 0 & 0 & 0 & $1(0.6 \%)$ \\
\hline Subtotal & 0 & 12 & 2 & 2 & 0 & $16(10.1 \%)$ \\
\hline Seawater & 0 & 0 & 0 & 1 & 0 & $1(0.6 \%)$ \\
\hline Total & $5(3.2 \%)$ & $65(41.1 \%)$ & $75(47.5 \%)$ & $11(7.0 \%)$ & $3(1.9 \%)$ & $158(100 \%)$ \\
\hline
\end{tabular}

tors and $\beta$-blockers being tested in $8.9 \%(n=14)$ and $4.4 \%$ $(n=7)$ of the trials, respectively. Other studied medications included angiostatic steroids $(n=6), \alpha_{2}$-adrenergic agonists $(n=4), 5-\mathrm{HT}_{2 \mathrm{~A}}(n=4)$, and NMDA receptor antagonists $(n=2)$.

\section{Discussion}

Investigations into medical treatments for glaucoma have shown compelling advances in the last 2 decades. This mostly US-based, industry-related research has produced a number of commercially available alternatives ranging from new drugs to sophisticated administration systems (such as fixed combinations). Clinical trials require costly and complex bureaucratic investments and infrastructure; therefore, they tend to be financed by companies from North America, Western Europe, and East Asia [11]. The high percentage of clinical trials performed in the USA might be explained by health care access inequality, inadequacy, and poverty, as low-income minority males tend to be disproportionally recruited; these trials can be important income providers for subjects [12]. Another possible reason for US- or EU-centred trials could be that the regulatory bodies from these highincome markets (i.e., the FDA and EMA) require trials to be performed in certified centres in their own countries or regions.

In addition to IOP-lowering potency, drug clinical trials are also used to determine safety profiles, specific target populations, different drug concentrations, and even fixed associations. For instance, the high number of studies on prostaglandin analogues refers to the interest that this class of drugs has created, along with trials testing these molecules involving issues such as preservative-free formulations, different regimens, and whether their effect can be maximized by associating them with a second drug class (such as a $\beta$-blocker) in a fixed combination [13]. This last point is particularly important, as the majority of glaucoma patients are not sufficiently controlled with a single drug [14]. As a result, double, triple, or even quadruple therapy is required to achieve the IOP target. However, even if tolerated initially, long-term complex multi-therapy does have its disadvantages. In this case, 
research into fixed-combination therapy is based on a number of potential advantages, including reduced exposure to preservatives, a reduced risk of preservative-related ocular surface disease symptoms, the elimination of washout associated with insufficient time separation of instillations, and reduced numbers of total instillations [15]. Furthermore, due to simplification of the instillation regimen, fixed combinations may improve treatment adherence and persistence. Therefore, fixed combinations enhance the stability of IOP control over time [16-18].

The toxic effects of preservatives are dose dependent and cumulative. These substances tend to be responsible for disease of the ocular surface and have also been associated with increased intraocular inflammation after surgery $[19,20]$. The development of clinical trials for preservative-free glaucoma drug formulations is also important for the evaluation of the possible pharmacokinetic differences [21].

The mechanism of action of the majority of glaucoma drugs tested in the registered trials was IOP modulation. An actin-related agent tested in these trials was latrunculin B. This agent is a macrolide that originated from a sponge from the Red Sea (Latrunculia). It inhibits the assembly of actin microfilaments by binding to free actin monomers in the cytoplasm, inducing cellular relaxation and weaker contacts between the cells and the matrix [22]. In a smooth-muscle-independent pathway, trabedonoson is a highly selective adenosine receptor agonist that improves flow by upregulating various proteases that remove accumulated proteins that can impair trabecular flow [23]. Angiostatic steroids have also been tested as possible IOP-lowering molecules for this disease. One of the tested molecules was anecortave acetate, which is a synthetic molecule derived from cortisol [24]. The 5-hydroxy-tryptamine $\left(5 \mathrm{HT}_{2 \mathrm{~A}}\right)$ agonists have also been evaluated as IOP-lowering agents in some clinical trials $(n=4)$. They represent a new mechanism of action [25], which is also the case with cyclin-dependent kinase (CDK) inhibitors [14] and LIM-domain kinase 2 inhibitors. The latter is a kinase associated with the regulation of the IOP, and its inhibition enhances fluid trabecular outflow.

Neuroprotection represents an emerging therapeutic approach for the treatment of primary open-angle glaucoma. Saving retinal ganglion cells and repairing damaged neurons could therefore be achieved not only by decreasing IOP but also by avoiding ischaemia, oxidative stress, excitotoxicity, defective axonal transport, trophic factor withdrawal, and neuroinflammation [3]. NMDA receptor antagonists, such as memantine, were tested in $1.3 \%$ of the clinical trials. Decreasing excitotoxicity is the

Drug Development for Glaucoma in the Last 20 Years mechanism of action, by reducing the excessive amounts of glutamate. A catechin (epigallocatechin-gallate) was also investigated as a neuroprotective agent. This is a powerful antioxidant with a proposed effect on the inner retinal function in eyes with early-to-moderate glaucomatous damage [26].

Some of the drugs tested in the clinical trials were able to combine mechanisms of action, modulate IOP, and provide neuroprotection. Interestingly, there appears to be an active interest in trabecular meshwork-acting drugs. Of these, Rho-kinase inhibitors are currently the most studied, with 11 trials in phase 2 . These agents relax the trabecular meshwork by inhibiting the actin of the contractile smooth muscle of the cytoskeleton, increasing the trabecular aqueous outflow [27]. In addition, these agents are progressively being recognized to have neuroprotective activity [28].

Two clinical trials with more particular approaches were also defined. A clinical trial from Iran on the use of saffron as an IOP-lowering agent was registered. Saffron has high concentrations of 2 carotenoid-related components, crocin and crocetin, with antioxidant properties [29]. The role of oxidative stress in primary open-angle glaucoma has been documented $[30,31]$. The trabecular matrix is sensitive to oxidative stress, and disturbed cell homeostasis in this tissue may cause structural changes that impair aqueous humour outflow and lead to an IOP increase. The antioxidant neuroprotective properties may also help in preventing glaucomatous optic neuropathy [32]. Microglial activation in the early stages has been shown to be an indicator of neurodegeneration severity in glaucoma. A recently published study has investigated the role of crocin in the inhibition of lipopolysaccharide-induced microglial activation, and determined that crocin effectively suppresses microglial activation and NF- $\mathrm{\kappa B} / \mathrm{YY} 1$ signalling, inducing an upregulation of CX3CR1 expression [33].

A clinical trial with the aim of studying the combined use of seawater and magnetic therapy is currently registered in the USA. However, no scientific rationale for this intervention is provided.

An important observation was the increase in the number of phase 1 trials that were registered when comparing the first decade evaluated with the second (from 0 trials in 1995-2005 to 5 in 2006-2015). This pattern is also reflected in the growing rate of registered phase 2 and 3 trials. The implementation of laws regulating the necessity of and improvements in clinical trial registration might be responsible for the apparent growth in the number of glaucoma trials [34]. Furthermore, even in the re-

Ophthalmic Res 2017;57:201-207 205 
gions where clinical trials are regulated and compulsory, laws tend to exclude all trial types, e.g., phase 1 trials and device trials. This can lead to a limitation in the number of phase 1 trials that are registered [35].

One key aspect of this query is that it demonstrated a certain proportion of the studies registered at these official platforms did not provide all the required information. This is important, as lack of information could undermine the scrutiny of ongoing trials, as required by the Declaration of Helsinki. In principle, no missing data should occur in queries like ours, as any lack of data potentially limits interpretation. Since the International Committee of Medical Journal Editors (ICMJE) determined in 2005 that clinical trials being considered for publication must be registered in publicly accessible registries, the number of registrations and the standards of data registration have increased $[7,8]$.

\section{Conclusion}

The medical treatment of glaucoma is an evolving field focused on strategies that include developing new drugs and optimizing existing therapies by testing fixed associations. While the last 2 decades have made prostaglandin analogues one of the first-line treatments in this field, there is also a large investment in novel compounds such as Rho-kinase inhibitors. Despite the small number of phase 1 trial registrations, the large number of trials currently in phase 3 could represent a broadening of medical options for glaucoma management in the near future.

\section{Disclosure Statement}

We have no conflicts of interest to disclose.

\section{References}

1 Tham YC, Li X, Wong TY, Quigley HA, Aung T, Cheng CY: Global prevalence of glaucoma and projections of glaucoma burden through 2040: a systematic review and meta-analysis. Ophthalmology 2014;121:2081-2090.

2 Maier PC, Funk J, Schwarzer G, Antes G, Falck-Ytter YT: Treatment of ocular hypertension and open angle glaucoma: meta-analysis of randomised controlled trials. BMJ 2005;331:134.

3 Wentz SM, Kim NJ, Wang J, Amireskandari A, Siesky B, Harris A: Novel therapies for open-angle glaucoma. F1000Prime Rep 2014; 6:102.

4 Reardon G, Kotak S, Schwartz GF: Objective assessment of compliance and persistence among patients treated for glaucoma and ocular hypertension: a systematic review. Patient Prefer Adherence 2011;5:441-463.

5 Cherecheanu AP, Garhofer G, Schmidl D, Werkmeister R, Schmetterer L: Ocular perfusion pressure and ocular blood flow in glaucoma. Curr Opin Pharmacol 2013;13:36-42.

6 Rocha-Sousa A, Rodrigues-Araujo J, Gouveia P, Barbosa-Breda J, Azevedo-Pinto S, PereiraSilva P, Leite-Moreira A: New therapeutic targets for intraocular pressure lowering. ISRN Ophthalmol 2013;2013:261386.

7 De Angelis C, et al: Clinical trial registration: a statement from the International Committee of Medical Journal Editors. N Engl J Med 2004;351:1250-1251.

8 Ghersi D, Pang T: From Mexico to Mali: four years in the history of clinical trial registration. J Evid Based Med 2009;2:1-7.

9 World Health Organization: International Standards for Clinical Trial Registries, November 2012.
10 Glanville JM, Duffy S, McCool R, Varley D: Searching ClinicalTrials.gov and the International Clinical Trials Registry Platform to inform systematic reviews: what are the optimal search approaches? J Med Lib Assoc 2014;102: 177-183.

11 Bothwell LE, et al: Assessing the gold standard - lessons from the history of RCTs. N Engl J Med 2016;374:2175-2181.

12 Fisher JA: Medical Research for Hire: The Political Economy of Pharmaceutical Clinical Trials. New Brunswick, Rutgers University Press, 2009.

13 Rouland JF, Le Pen C: Naturalistic, prospective study of glaucoma and ocular hypertension treatment in France: strategies, clinical outcomes, and costs at 1 year. Eur J Ophthalmol 2003;13:5-20.

14 Galons H, Oumata N, Meijer L: Cyclin-dependent kinase inhibitors: a survey of recent patent literature. Expert Opin Ther Pat 2010; 20:377-404.

15 Aptel F, Chiquet C, Romanet JP: Intraocular pressure-lowering combination therapies with prostaglandin analogues. Drugs 2012;72: 1355-1371.

16 Hommer A: Role of fixed combinations in the management of open-angle glaucoma. Expert Rev Pharmacoecon Outcomes Res 2011;11: 91-99.

17 Holló G, Topouzis F, Fechtner RD: Fixedcombination intraocular pressure-lowering therapy for glaucoma and ocular hypertension: advantages in clinical practice. Expert Opin Pharmacother 2014;15:1737-1747.
18 European Glaucoma Society: Terminology and Guidelines for Glaucoma. Savona, Publicomm, 2014, pp 75-127.

19 Stalmans I, Sunaric Mégevand G, Cordeiro MF, Hommer A, Rossetti L, Goñi F, Heijl A, Bron A: Preservative-free treatment in glaucoma: who, when, and why? Eur J Ophthalmol 2013;23:518-525.

20 Stevens AM, Kestelyn PA, De Bacquer D, Kestelyn PG: Benzalkonium chloride induces anterior chamber inflammation in previously untreated patients with ocular hypertension as measured by flare meter: a randomized clinical trial. Acta Ophthalmol 2012;90:e221e224.

21 Bagnis A, Papadia M, Scotto R, Traverso CE: Antiglaucoma drugs: the role of preservativefree formulations. Saudi J Ophthalmol 2011; 25:389-394.

22 Rasmussen CA, Kaufman PL, Ritch R, Haque R, Brazzell RK, Vittitow JL: Latrunculin B reduces intraocular pressure in human ocular hypertension and primary open-angle glaucoma. Transl Vis Sci Technol 2014;3:1.

23 Kopczynski C, Epstein D: Emerging trabecular outflow drugs. J Ocul Pharmacol Ther 2014;30:85-87.

24 Robin AL, Suan EP, Sjaarda RN, Callanan DG, Defaller J; Alcon Anecortave Acetate for IOP Research Team: Reduction of intraocular pressure with anecortave acetate in eyes with ocular steroid injection-related glaucoma. Arch Ophthalmol 2009;127:173-178.

25 Carta F, Supuran CT, Scozzafava A: Novel therapies for glaucoma: a patent review 20072011. Expert Opin Ther Pat 2012;22:79-88. 
26 Falsini B, Marangoni D, Salgarello T, Stifano G, Montrone L, Di Landro S, Guccione L, Balestrazzi E, Colotto A: Effect of epigallocatechin-gallate on inner retinal function in ocular hypertension and glaucoma: a short-term study by pattern electroretinogram. Graefes Arch Clin Exp Ophthalmol 2009;247:12231233.

27 Green J, Cao J, Bandarage UK, Gao H, Court J, Marhefka C, Jacobs M, Taslimi P, Newsome D, Nakayama T, Shah S, Rodems S: Design, synthesis, and structure-activity relationships of pyridine-based rho kinase (ROCK) inhibitors. J Med Chem 2015;58:5028-5037.

28 Van de Velde S, De Groef L, Stalmans I, Moons L, Van Hove I: Towards axonal regeneration and neuroprotection in glaucoma: Rho kinase inhibitors as promising therapeutics. Prog Neurobiol 2015;131:105-119.
29 Khazdair MR, Boskabady MH, Hosseini M, Rezaee R, Tsatsakis AM: The effects of Crocus sativus (saffron) and its constituents on nervous system: a review. Avicenna J Phytomed 2015;5:376-391.

30 Izzotti $\mathrm{A}$, Saccà SC, Longobardi $\mathrm{M}$, Cartiglia C: Mitochondrial damage in the trabecular meshwork of patients with glaucoma. Arch Ophthalmol 2010;128:724-730.

31 Erdurmus M, Yağc1 R, Atıs Ö, Karadağ R, Akbaş A, Hepşen IF: Antioxidant status and oxidative stress in primary open angle glaucoma and pseudoexfoliative glaucoma. Curr Eye Res 2011;36:713-718.
32 Jabbarpoor Bonyadi MH, Yazdani S, Saadat S: The ocular hypotensive effect of saffron extract in primary open angle glaucoma: a pilot study. BMC Complement Altern Med 2014; 14:399.

33 Lv B, Huo F, Zhu Z, Xu Z, Dang X, Chen $\mathrm{T}$, Zhang $\mathrm{T}$, Yang $\mathrm{X}$ : Crocin upregulates CX3CR1 expression by suppressing NF- $\mathrm{KB} /$ YY1 signaling and inhibiting lipopolysaccharide-induced microglial activation. Neurochem Res 2016;41:1949-1957.

34 Zarin DA, Tse T, Sheehan J: The proposed rule for U.S. clinical trial registration and results submission. N Engl J Med 2015;372: 174-180.

35 Viergever RF, Li K: Trends in global clinical trial registration: an analysis of numbers of registered clinical trials in different parts of the world from 2004 to 2013. BMJ Open 2015; 5:e008932.
Drug Development for Glaucoma in the Last 20 Years
Ophthalmic Res 2017;57:201-207 DOI: $10.1159 / 000453527$ 